\title{
Spatial Analysis of Bifenthrin Sediment and Water Concentrations in California Waterbodies from 2001 to 2017
}

\author{
Lenwood W. Hall Jr and Ronald D. Anderson \\ Additional information is available at the end of the chapter \\ http://dx.doi.org/10.5772/intechopen.76835
}

\begin{abstract}
The objective of this study was to summarize and map bifenthrin sediment and water column monitoring data from California waterbodies (2001-2017) and determine where detected bifenthrin concentrations were reported and potential toxicity to aquatic biota may exist. Bifenthrin sediment data based on targeted sampling in depositional areas were available for more sites (982) than water column data (716 sites), and sediment sites had a lower percent of nondetected concentrations $(36 \%)$ when compared with water values (77\%). Comparison of results from three ambient sediment toxicity tests from sediment sites and six ambient toxicity tests from water sites showed no toxicity from $43 \%$ of the sediment sites and $65 \%$ of the water sites. A comparison of sediment measurements with acute toxicity data from two test species (Hyalella azteca and Chironomus tentans) showed no toxicity at $80-99.5 \%$ of the sites. Bifenthrin total water concentrations compared with a proposed 2015 chronic criterion of $0.01 \mathrm{ng} / \mathrm{L}$ showed no exceedances at $77 \%$ of the sites. Due to the conservative assumptions used in this analysis, bifenthrin ecological risk to aquatic life in California water bodies from both sediment exposure based on only targeted sampling from depositional areas and water column exposures based on using only total concentrations (not the bioavailable phase) is generally judged to be low statewide.
\end{abstract}

Keywords: bifenthrin monitoring, bifenthrin toxicity, California water bodies, depositional areas

\section{Introduction}

Pyrethroids are a class of insecticides that are registered for use in both agricultural and urban areas. These insecticides are specifically registered for use on a wide variety of agricultural crops, 
home and garden, landscaping, nurseries, structural sites, vector control and golf courses [1]. In recent years, pyrethroid use in urban areas of California has increased as the use of organophosphate insecticides has declined [2]. Agricultural use of pyrethroids has remained relatively stable over the past decade in California with some exceptions such as increased use on almonds and fruit production concurrently with reductions in organophosphate use [3].

Water column and sediment toxicity data from water bodies in the State of California from 2001 to 2009 were summarized by Hunt et al. [4]. These investigators reported that organophosphates and more recently pyrethroids were the primary pesticides suspected in causing toxicity. For the pyrethroids, bifenthrin was the specific pyrethroid that was implicated in causing toxicity more frequently in both sediment and water than the other pyrethroids based on toxicity identification evaluations (TIEs). Hunt et al. [4] displayed the results of their analysis using a series of maps, and the general "Big Picture" message from these maps is that sediment and water column toxicity (i.e., from pesticides such as bifenthrin) is widespread throughout California. What is lacking in the Hunt et al. [4] analysis is an objective presentation of data from California water bodies showing sites where bifenthrin has been measured in sediment and water (including both detected and non-detected concentrations) and corresponding toxicity or lack of toxicity has been reported. A previous analysis was conducted where the California bifenthrin sediment data but not water column data were summarized from 2001 to 2010 [5]. The general objective of this study was to update the bifenthrin sediment analysis and include water column data to address the research question described above using data collected from 2001 to 2017 in California water bodies.

The specific objectives of this study were to collect and summarize bifenthrin sediment and water column monitoring and corresponding toxicity data from 2001 to 2017 in order to develop a series of maps in California water bodies to show the following: (1) all sites where bifenthrin measurements in sediment and water have been conducted; (2) identify from this universe of sites which sites have non-detected and detected concentrations of bifenthrin in sediment and water (e.g., bifenthrin measurements were made but concentrations were below or above the level of detection); (3) identify from this universe of sites which sites have significant ambient toxicity, nonsignificant ambient toxicity, or mixed results based on concurrent ambient sediment and water toxicity tests and bifenthrin measurements; (4) identify sites with significant ambient toxicity with co-occurring nondetected bifenthrin sediment and water concentrations (toxicity due to stressors other than bifenthrin) and (5) identify the sites showing significant sediment toxicity where bifenthrin is implicated as a contributor to the toxicity based on comparisons with acute laboratory sediment toxicity values with Hyalella azteca and Chironomus tentans (dilutus) (geometric mean of multiple values used for each species) or significant water column toxicity is implicated based on a comparison with species sensitivity distributions (SSD) fifth centile of $14.4 \mathrm{ng} / \mathrm{L}$ or proposed acute $(0.06 \mathrm{ng} / \mathrm{L})$ or chronic $(0.01 \mathrm{ng} / \mathrm{L})$ criteria [6].

\section{Methods}

The primary source of all data used in this study was the California Environmental Data Exchange Network (CEDEN), which was also the primary data source used by Hunt et al. [4] 
in their analysis. CEDEN data are considered high-quality data compatible with California's Surface Water Ambient Monitoring Program (SWAMP). We also used sediment and water column chemistry and toxicity data from Central Valley Water Quality Coalitions and our own data sets (University of Maryland) if these data sets were not available in CEDEN.

The first step of this project was to identify and obtain bifenthrin sediment and water column monitoring data and ambient sediment and water column toxicity data from California water bodies from CEDEN in order to develop a series of maps. Coordinates for the sites were required if the bifenthrin data were used in the maps, and in some cases, a web research was used to determine site coordinates when they were not provided in the CEDEN database. Coordinates for all sites are presented in other reports [7, 8]. Only sediment data with concurrent total organic carbon (TOC) data were used in the analysis. All sediment sites were from depositional areas (fine grain sediment). All the water column monitoring data were from whole water samples (not filtered or dissolved fraction).

Multiple acceptable acute sediment toxicity values were available for both the amphipod Hyalella azteca and the midge Chironomus tentans (dilutes) as presented in Table 1 [9-15]. The geometric mean of five Hyalella azteca acute toxicity values normalized to $1 \%$ TOC was $6.1 \mathrm{ng} / \mathrm{g}$. The geometric mean of three Chironomus tentans (dilutus) toxicity values was $177.5 \mathrm{ng} / \mathrm{g}$ normalized to $1 \%$ TOC. Both the bifenthrin sediment measurements and the toxicity values were normalized to $1 \%$ TOC to allow for an accurate comparison. There were no California bifenthrin sediment quality criteria that could be used for comparison with field measurements.

Bifenthrin acute water column toxicity data from laboratory studies (generally clean filtered water) were available for 17 species as presented in Table 2 [16-28]. These data were used to develop a species sensitivity distribution (SSD) using a log normal distribution with a corresponding fifth centile of $14.4 \mathrm{ng} / \mathrm{L}$ as presented in Figure 1. Bifenthrin total water column concentrations were compared with this fifth centile to determine the frequency of exceedances. We also

\begin{tabular}{llll}
\hline Species & 10-day LC50 (ng/g) & Geometric mean & Reference \\
\hline H. azteca & 5.1 & & {$[9]$} \\
& 10.1 & {$[10]$} & {$[11]$} \\
& 8.3 & & {$[12]$} \\
& 9.9 & & {$[13]$} \\
& 2.0 & 6.1 & {$[13]$} \\
C. tentans & & {$[14]$} \\
& 81 & & {$[15]$} \\
\hline
\end{tabular}

Table 1. Acute (10-day) freshwater sediment toxicity data normalized to $1 \%$ TOC for Hyalella azteca and Chironomus tentans used to calculate a geometric mean for each species. These geometric means were compared with field bifenthrin sediment measurements normalized to $1 \%$ TOC as presented in Figures 5 and 6. 


\begin{tabular}{|c|c|c|c|}
\hline Species & Endpoint & Concentration (ng/L) & Reference \\
\hline Hyalella azteca & 96 h LC50 & 7.5 & Geomean: $[12,16]$ \\
\hline Procloeon sp. & 48 h LC50 & 84.3 & {$[16]$} \\
\hline Ceriodaphnia dubia & 96 h LC50 & 105 & Geomean: $[17,18]$ \\
\hline Gammarus pulex & 48 h LC50 & 110 & [19] \\
\hline Oncorhynchus mykiss & 96 h LC50 & 120 & Geomean: $[20,21]$ \\
\hline Trichoptera & 48 h LC50 & 180 & {$[19]$} \\
\hline Lepomis macrochirus & 96 h LC50 & 300 & Geomean: $[22,23]$ \\
\hline Hexagenia sp. & 48 h LC50 & 390 & [19] \\
\hline Pimephales promelas & 96 h LC50 & 405 & Geomean: $[24,25]$ \\
\hline Daphnia magna & $48 \mathrm{~h}$ EC50 & 420 & Geomean: $[26,27]$ \\
\hline Enallagma/Ischnura & 24 h LC50 & 1100 & {$[28]$} \\
\hline Simulium vittatum & 24 h LC50 & 1300 & {$[28]$} \\
\hline Heptageniidae & 24 h LC50 & 2300 & {$[28]$} \\
\hline Chironomus dilutus & 96 h LC50 & 2615 & {$[16]$} \\
\hline Hydrophilus spp. & 24 h LC50 & 5400 & {$[28]$} \\
\hline Thamnocephalus platyurus & 24 h LC50 & 5700 & {$[19]$} \\
\hline Hydropsyche/Cheumatopsyche & 24 h LC50 & 7200 & {$[28]$} \\
\hline
\end{tabular}

Table 2. Summary of acute water column bifenthrin toxicity data used to develop a species sensitivity distribution (SSD) and fifth centile.

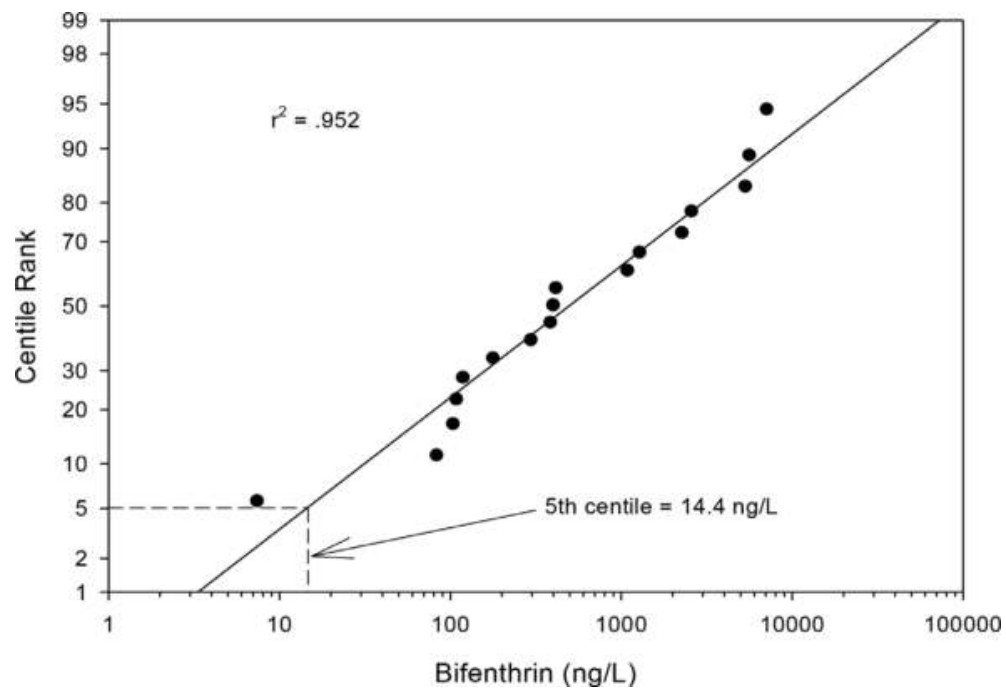

Figure 1. Species sensitivity distribution for bifenthrin based on a log-normal distribution from water column toxicity data for 17 species. The fifth centile was $14.4 \mathrm{ng} / \mathrm{L}$. 
compared the bifenthrin total water concentrations with the 2015 University of California Davis proposed acute criterion of $0.06 \mathrm{ng} / \mathrm{L}$ and proposed chronic criterion of $0.01 \mathrm{ng} / \mathrm{L}$ [6].

Maps were developed from Arcview using bifenthrin sediment and water column data summarized by site coordinates in Excel spread sheets. Bifenthrin acute ambient sediment toxicity data were available for Hyalella azteca, Chironomus tentans (dilutus) and Eohaustorius estuarius. Sediment maps comparing bifenthrin measurements with acute Hyalella azteca and Chironomus tentans (dilutus) single species sediment toxicity data values were developed at sites where concurrent total organic carbon (TOC) values were reported. For the water column data, maps were developed with concurrent water column measurements and concurrent ambient toxicity data with the following test species: water flea (Ceriodaphnia dubia); fathead minnow (Pimephales promelas); amphipod (Hyalella azteca); copepod (Eurytemora affinis); Topsmelt silverside (Atherinops affinis) and midge (Chironomus dilutes). Frequency of exceedance for all sediment and water column endpoints was determined. Maps were also developed for nondetected sediment and water concentrations and co-occurring ambient toxicity data to demonstrate toxicity, mixed results and no toxicity. If toxicity was reported and bifenthrin was not detected, then toxicity was attributed to other stressors.

\section{Results and discussion}

\subsection{Bifenthrin sediment data}

A total of 2312 bifenthrin sediment measurements normalized to 1\% TOC for California sites from 2001 to 2017 including site names, site coordinates, sampling dates, TOC, bifenthrin concentration (ng/g) and bifenthrin concentration normalized to $1 \%$ TOC (ng/g) are presented in a report [7]. Concentrations normalized to $1 \%$ TOC ranged from nondetected to $697.4 \mathrm{ng} / \mathrm{g}$. Many duplicate/composite bifenthrin measurements were removed from the dataset if the samples were collected within $1 \mathrm{~h}$ and had the exact same bifenthrin and TOC values. Bifenthrin sediment measurements with concurrent TOC values were available from 982 sites in California from 2001 to 2017 as presented in Figure 2. From a spatial perspective, these sediment sites appeared to represent most of the state, although most of these sites were in the Central Valley, Central Coast and Southern California.

Bifenthrin detection limits for nondetected measurements ranged from 0.025 to $1.00 \mathrm{ng} / \mathrm{g}$ for most of the data set. Detection limits ranged from 1.01 to $440 \mathrm{ng} / \mathrm{g}$ for 68 nondetected measurements that were removed from the dataset (prior to matching them with TOC data) because these high detection limits were judged to be unacceptable for the current analysis. Based on a review of CEDEN, it appears that all of these bifenthrin measurements were collected in depositional areas containing fine grain material such as silt and clay according to the SWAMP Protocols [29]. Therefore, these data do not represent the results of random sampling. This is a critical "ecological relevance issue" because the sediment from at least some of the water bodies sampled are dominated by non-depositional areas (larger grain deposited sediment such as sand or gravel) as previously reported [30]. These nondepositional areas generally do not accumulate hydrophobic chemicals such as bifenthrin. Hence, all the results presented below represent worst-case conditions from a watershed perspective because only sediment data from depositional areas are considered. 


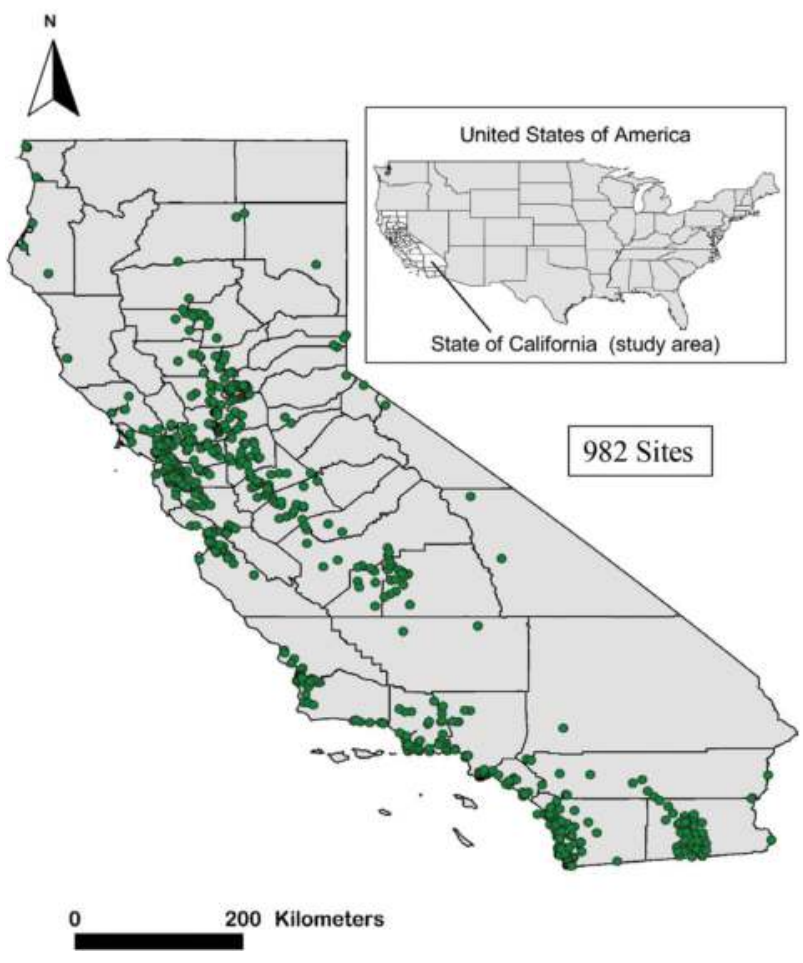

Figure 2. All California sediment sites (green dots) where samples were taken for bifenthrin with concurrent TOC measurements from 2001 to 2017.

Based on this universe of 982 sites, measurements below the level of detection were reported at 358 sites (36\%) while detected concentrations were reported at 516 sites (53\%) (Figure 3). Mixed results including both detected and non-detected concentrations were reported for 108 sites $(11 \%$ of the total).

Ambient sediment toxicity data based on Hyalella azteca, Chironomus dilutus, and Eohaustorius estuarius were available for 499 sites where concurrent bifenthrin measurements were reported. The following results were reported in Figure 4: (1) significant toxicity was reported at 180 sites (36\%); (2) nonsignificant toxicity was reported 212 sites (43\%) and (3) mixed results of significant and nonsignificant toxicity based on two or more tests were reported at 107 sites $(21 \%)$.

One percent TOC normalized bifenthrin measurements were reported from 982 sites to allow a comparison with both Hyalella and Chironomus acute laboratory toxicity values. Nondetected values with detection limits $\leq 1.00 \mathrm{ng} / \mathrm{g}$ were assigned a value of $1 / 2$ the detection limit for this analysis. Bifenthrin concentrations from these sites were compared with the geometric mean of five acute Hyalella azteca toxicity values in Table 1 normalized to $1 \%$ TOC $(6.1 \mathrm{ng} / \mathrm{g})$. The results of this analysis in Figure 5 showed the following: (1) bifenthrin measurements below 


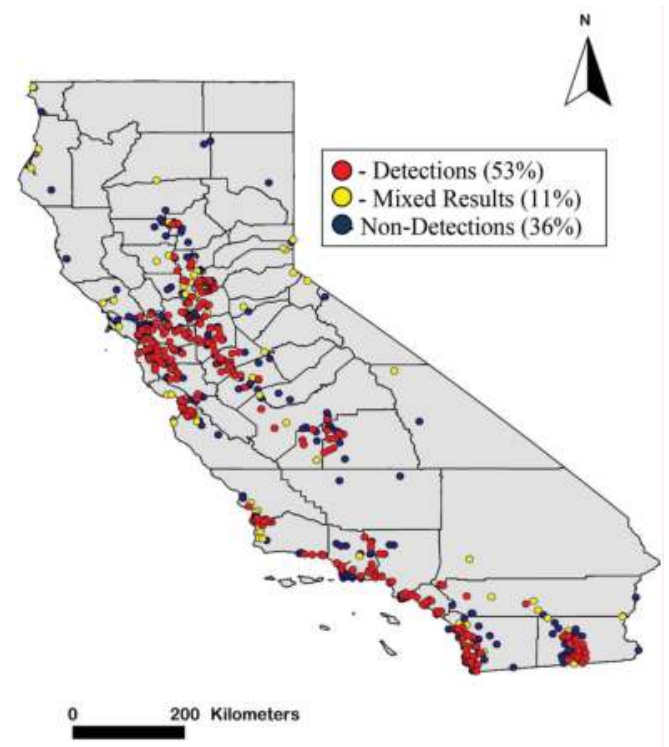

Figure 3. California bifenthrin sediment monitoring sites from 2001 to 2017 with detected concentrations only (red dots), nondetected concentrations only (blue dots) and mixed results of detected or non-detected concentrations on two or more sampling events (yellow dots).

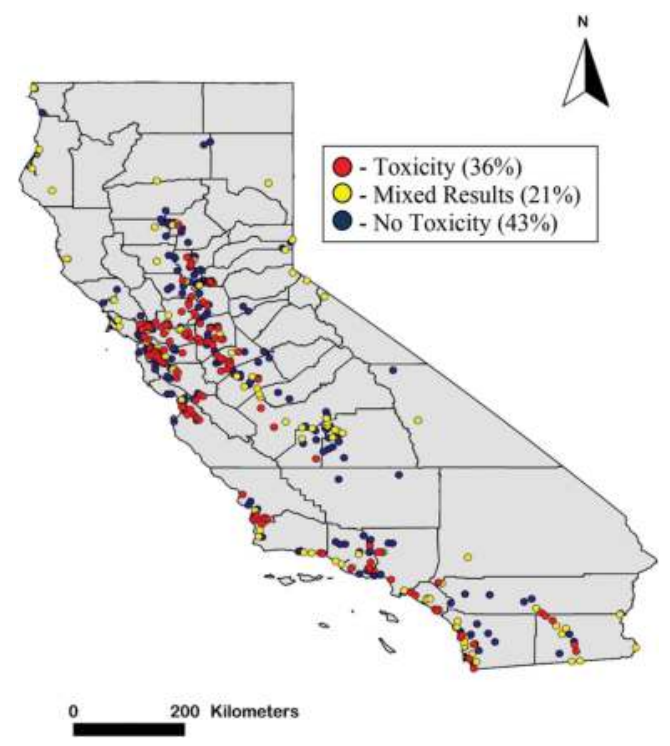

Figure 4. California bifenthrin sediment monitoring sites from 2001 to 2017 with significant ambient sediment toxicity (red dots), no significant ambient sediment toxicity (blue dots) and mixed results of significant and nonsignificant ambient toxicity based on two or more tests (yellow dots). 


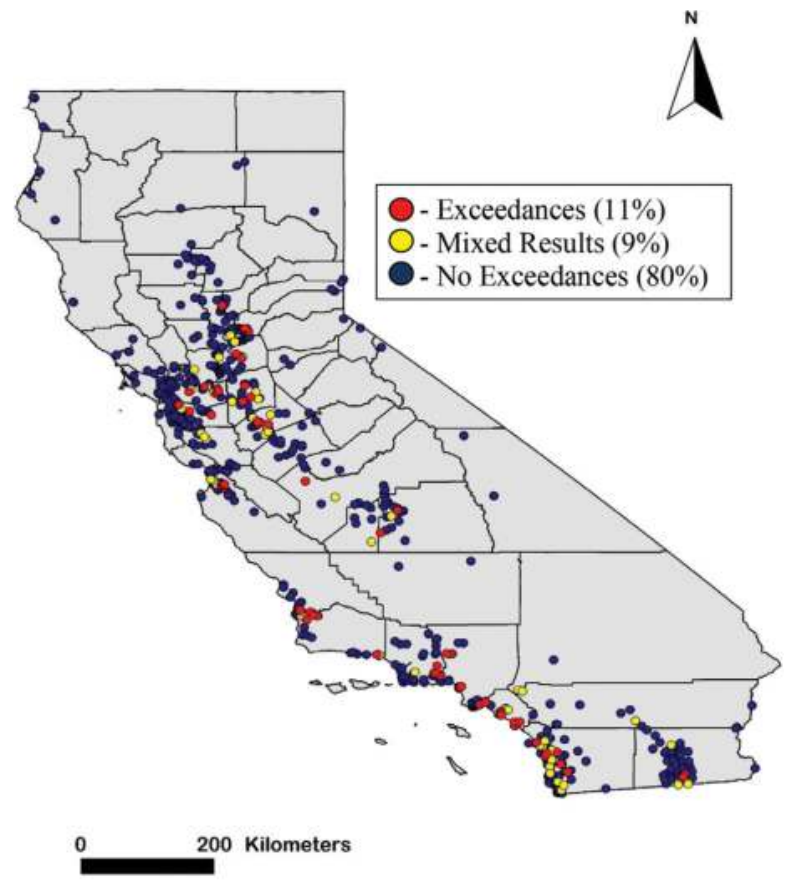

Figure 5. California bifenthrin sediment monitoring sites from 2001 to 2017 that exceeded the $1 \%$ TOC normalized $(6.1 \mathrm{ng} / \mathrm{g}) \mathrm{H}$. azteca sediment toxicity value (red dots) did not exceed the sediment toxicity value (blue dots) and mixed results of exceeding and not exceeding the sediment toxicity value based on two or more measurements (yellow dots).

$6.1 \mathrm{ng} / \mathrm{g}$ were reported at 786 sites (80\%); (2) bifenthrin measurements above $6.1 \mathrm{ng} / \mathrm{g}$ were reported at 103 sites (11\%) and (3) mixed results were reported for 93 sites (9\%).

The 1\% TOC normalized bifenthrin values from 982 sites were compared with the geometric mean of three $1 \%$ TOC normalized Chironomus tentans (dilutus) acute toxicity values (177.5 ng/ $\mathrm{g}$ in Table 1) presented in Figure 6. There were no exceedances of the $177.5 \mathrm{ng} / \mathrm{g}$ value for 99.5\% of the sites. There were only two sites (Del Puerto Creek at Highway 33/Mulberry Road and Santa Clara River (403S39062) - see [7]) where the Chironomus acute value was exceeded $(0.2 \%)$ and three sites (Alamo River Outlet, Bouquet Canyon Creek and Dual Storm Drain at Opal and Parkside Way) where mixed results of exceedances and nonexceedances $(0.3 \%)$ were reported.

In the absence of sediment criteria, this begs the question of which species (Hyalella or Chironomus) should be used to determine toxicity in California water bodies. Hyalella is clearly much more sensitive to pyrethroids such as bifenthrin [31], but the case could certainly be made that Chironomus, which is a chironomid that is both dominant and representative in many California water bodies [32] may be more appropriate for assessing toxicity. Another "weight of evidence" approach to also consider is to use a suite of toxicity tests with a number 


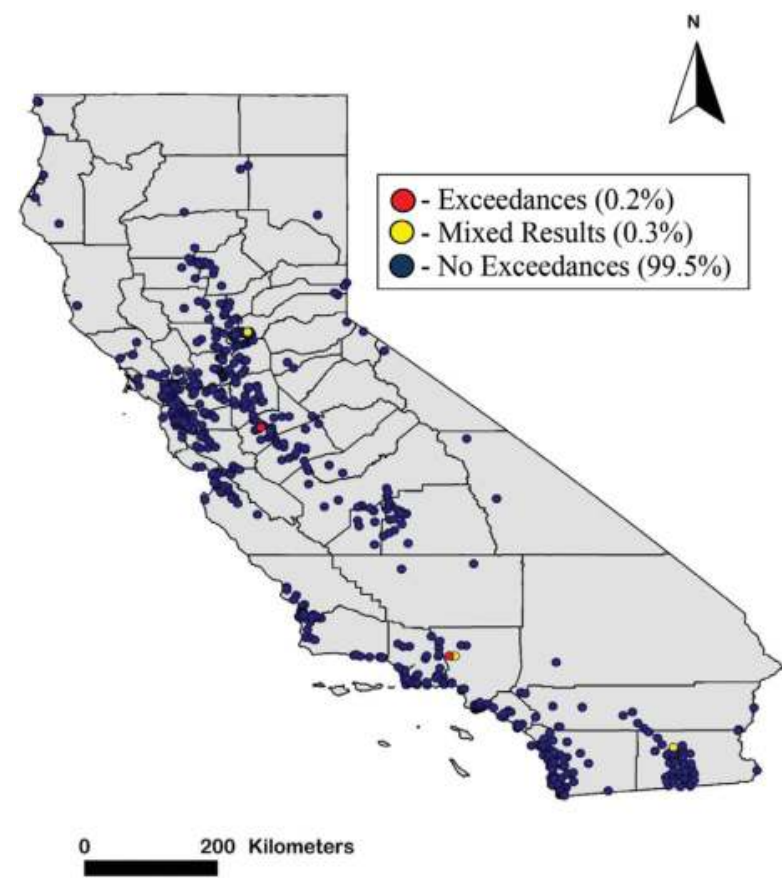

Figure 6. California bifenthrin sediment monitoring sites from 2001 to 2017 that exceeded the 1\% TOC normalized (177.5 ng/g) C. tentans acute sediment toxicity value (red dots) did not exceed the sediment toxicity value (blue dots) and mixed results of exceeding and not exceeding the sediment toxicity value (yellow dots).

of different test species before a final judgment is made for determining toxicity in a water body. This approach has been used and accepted in other areas of the United States such as the Chesapeake Bay [33].

There were 244 California sediment sites sampled from 2001 to 2017 with nondetected concentrations of bifenthrin and co-occurring ambient sediment toxicity data as presented in Figure 7. Sixty-four percent of these sites had nondetected bifenthrin sediment concentrations and no significant toxicity. Thirty-six percent of these sites had nondetected bifenthrin sediment concentrations with some significant sediment toxicity which indicates that toxicity at these sites is caused by stressors other than bifenthrin.

\subsection{Bifenthrin water column data}

Bifenthrin water column concentrations from California sites from 2001 to 2017 including site names, sampling dates, coordinates, bifenthrin concentrations $(\mathrm{ng} / \mathrm{L})$ are presented in a report [8]. Water column concentrations of bifenthrin based on 3256 measurements ranged from nondetected to $5634 \mathrm{ng} / \mathrm{L}$ (influent sample at wastewater treatment facility) with only $16 \%$ of the measurements above the level of detection. Bifenthrin detection limits for nondetected values 


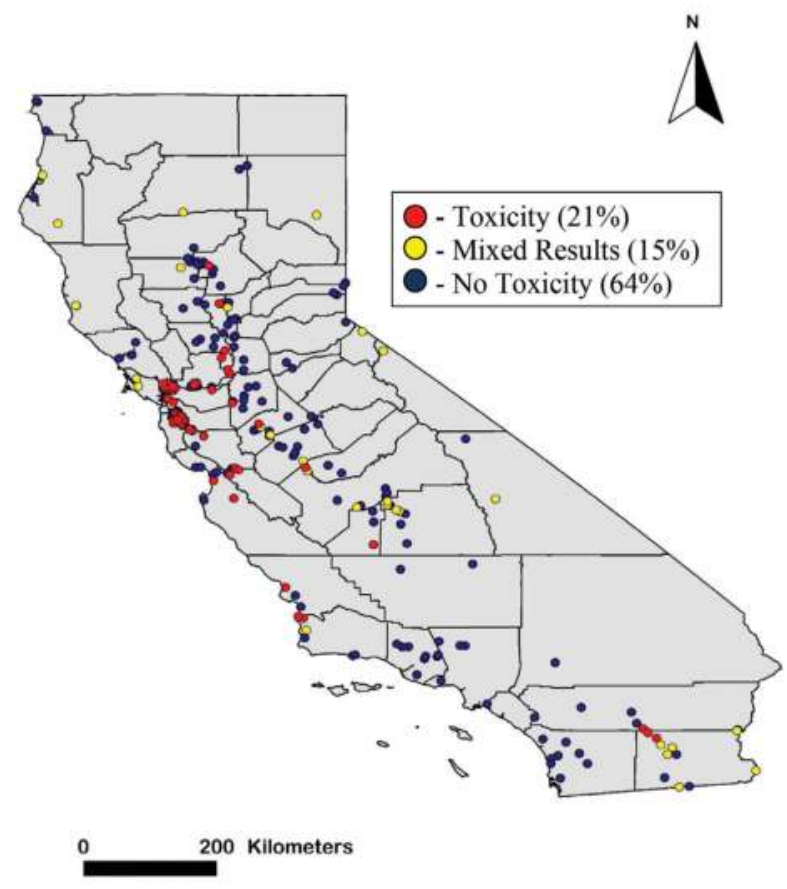

Figure 7. California bifenthrin sediment monitoring sites from 2001 to 2017 with nondetected bifenthrin concentrations and significant ambient sediment toxicity (red dots), no significant ambient sediment toxicity (blue dots) and mixed results of significant and non-significant ambient sediment toxicity based on two or more tests (yellow dots).

ranged from 0.1 to $6 \mathrm{ng} / \mathrm{L}$ and the range for detected values ranged was $0.05-17.0 \mathrm{ng} / \mathrm{L}$. Nondetected measurements from 84 samples with extremely high detection limits $(6.44-400 \mathrm{ng} / \mathrm{L})$ were removed from the dataset because these detection limits were substantially higher than proposed effect thresholds.

Bifenthrin water column measurements were available from 716 sites in California from 2001 to 2017 as presented in Figure 8. Most of the bifenthrin water measurements were conducted in the Central Valley, Central Coast or southern areas of California. Based on this universe of 716 sites, 549 sites $(77 \%)$ had nondetected values while detected concentrations were reported at 63 sites (9\%) (Figure 9). Mixed results of both detected and nondetected concentrations by site were reported at 104 sites (14\%). In Figure 10, ambient water column toxicity data based on the following single species ambient tests were available for 467 sites where concurrent bifenthrin measurements were conducted: Ceriodaphnia dubia (1438 tests); Pimephales promelas (1155 tests); Hyalella azteca (527 tests); Eurytemora affinis (25 tests); Atherinops affinis (20 tests); and Chironomus dilutus (23 tests). No significant toxicity was reported at 304 sites (65\%) while mixed results of significant and no significant toxicity at a site or significant toxicity at a site was reported at 163 sites (35\%). 


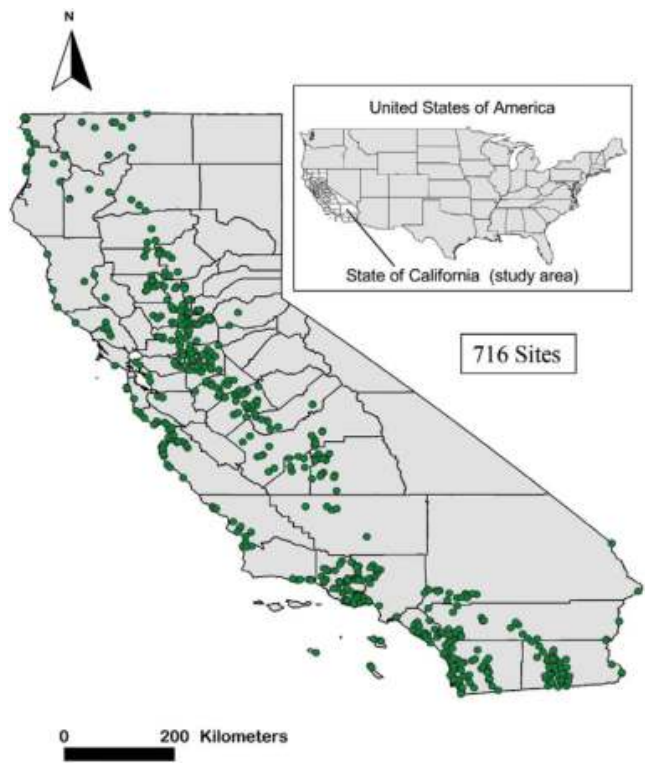

Figure 8. All California water column sites (green dots) where samples were taken for bifenthrin from 2001 to 2017.

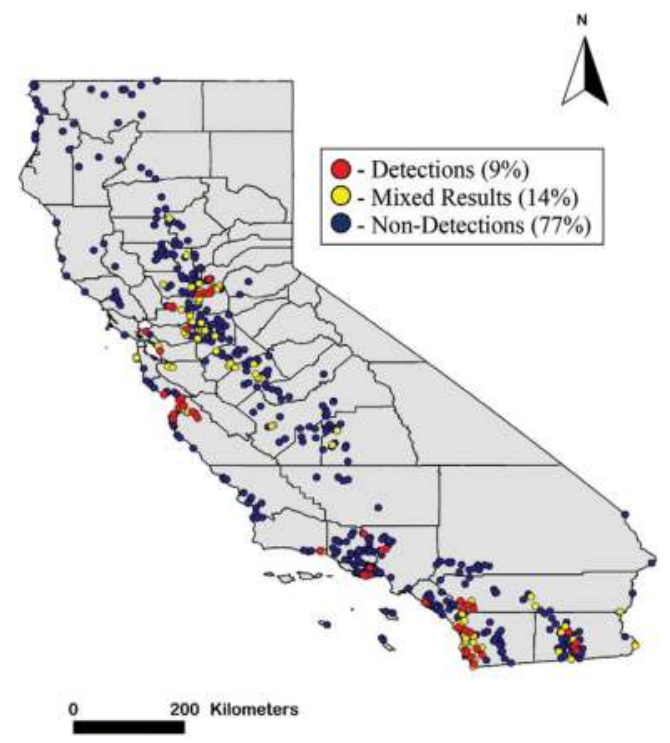

Figure 9. California bifenthrin water column monitoring sites from 2001 to 2017 with detected concentrations only (red dots), nondetected concentrations only (blue dots) and mixed results of detected or nondetected concentrations on two or more dates (yellow dots). 


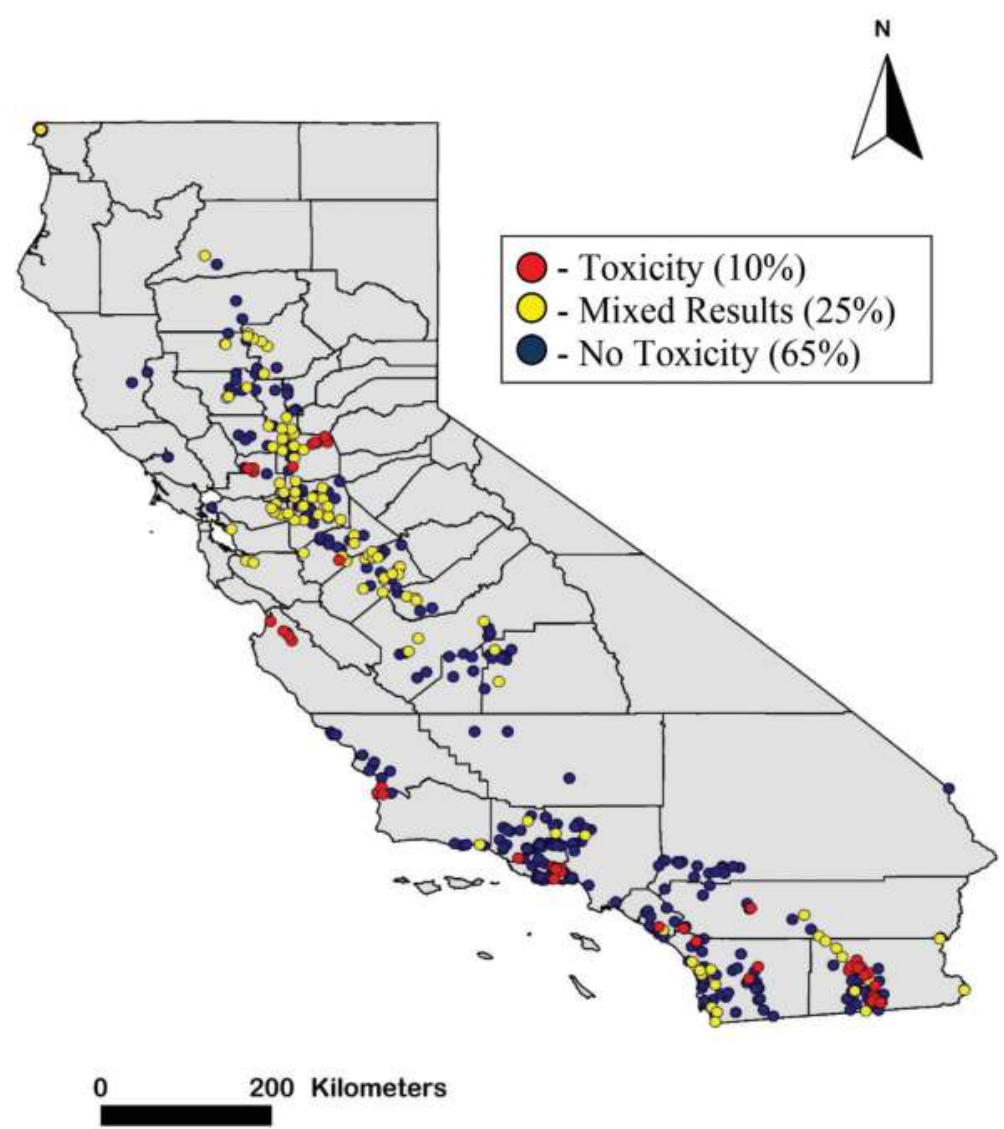

Figure 10. California bifenthrin water column monitoring sites from 2001 to 2017 (467 sites) with significant ambient water column toxicity (red dots), no significant ambient water column toxicity (blue dots) and mixed results of significant and nonsignificant ambient toxicity based on two or more tests (yellow dots).

There were 429 California water sites sampled from 2001 to 2017 with nondetected concentrations of bifenthrin in water and co-occurring water column toxicity data as presented in Figure 11. The data presented in Figure 11 showed the following: (1) 69\% of the sites showed nondetected bifenthrin concentrations and no significant toxicity and (2) 31\% of the sites showed nondetected bifenthrin concentrations with significant toxicity (or mixed results) which suggests that toxicity at these sites is due to factors other than bifenthrin.

Bifenthrin water column concentrations from 716 sites were compared with the fifth centile of $14.4 \mathrm{ng} / \mathrm{L}$ from an SSD (Figure 1) to determine which sites had exceedances of this fifth centile (Figure 12). There were no exceedances of the $14.4 \mathrm{ng} / \mathrm{L}$ fifth centile at 630 sites (88\%) while 64 sites $(9 \%)$ had mixed results of exceedances/no exceedances based on two or more samples (Figure 12). The SSD fifth centile was exceeded at 22 sites (3\%). 


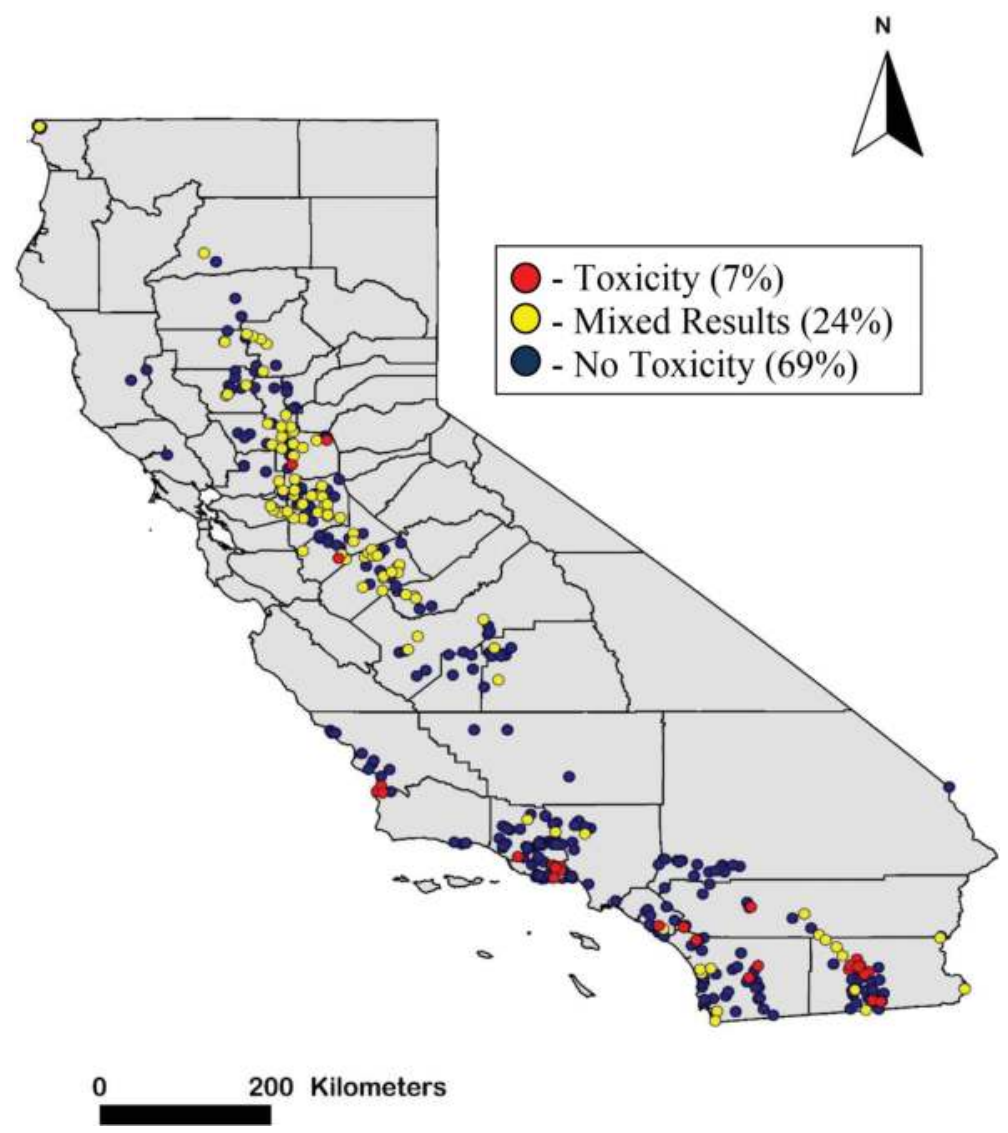

Figure 11. California bifenthrin water column monitoring sites from 2001 to 2017 (429 sites) with non-detected bifenthrin concentrations and significant ambient water column toxicity (red dots), no significant ambient water column toxicity (blue dots) and mixed results of significant and nonsignificant ambient water column toxicity based on two or more tests (yellow dots).

Bifenthrin water column monitoring data were also compared with the 2015 proposed acute criterion of $0.06 \mathrm{ng} / \mathrm{L}$ [6]. Exceedances of the $0.06 \mathrm{ng} / \mathrm{L}$ acute value in Figure 13 showed: (1) there were no exceedances of the $0.06 \mathrm{ng} / \mathrm{L}$ acute value for $77 \%$ of the sites (554); (2) there were exceedances of the acute criterion for $9 \%$ the sites (63); and (3) there were mixed results of exceedances and no exceedances for $14 \%$ of the sites (104). The percent exceedance calculations for the $0.01 \mathrm{ng} / \mathrm{L}$ proposed chronic criterion in Figure 14 were: (1) there were no exceedances of the $0.01 \mathrm{ng} / \mathrm{L}$ chronic criterion for $77 \%$ of the sites (549); (2) there were exceedances of the chronic criterion for 9\% the sites (63); and (3) there were mixed results of exceedances and no exceedances for $14 \%$ of the sites (104). Various categories of exceedances (exceedances, mixed results and no exceedances) were identical in Figures $\mathbf{1 3}$ and $\mathbf{1 4}$ thus demonstrating that at least for bifenthrin water monitoring data based on total concentrations the proposed $0.06 \mathrm{ng} / \mathrm{L}$ 


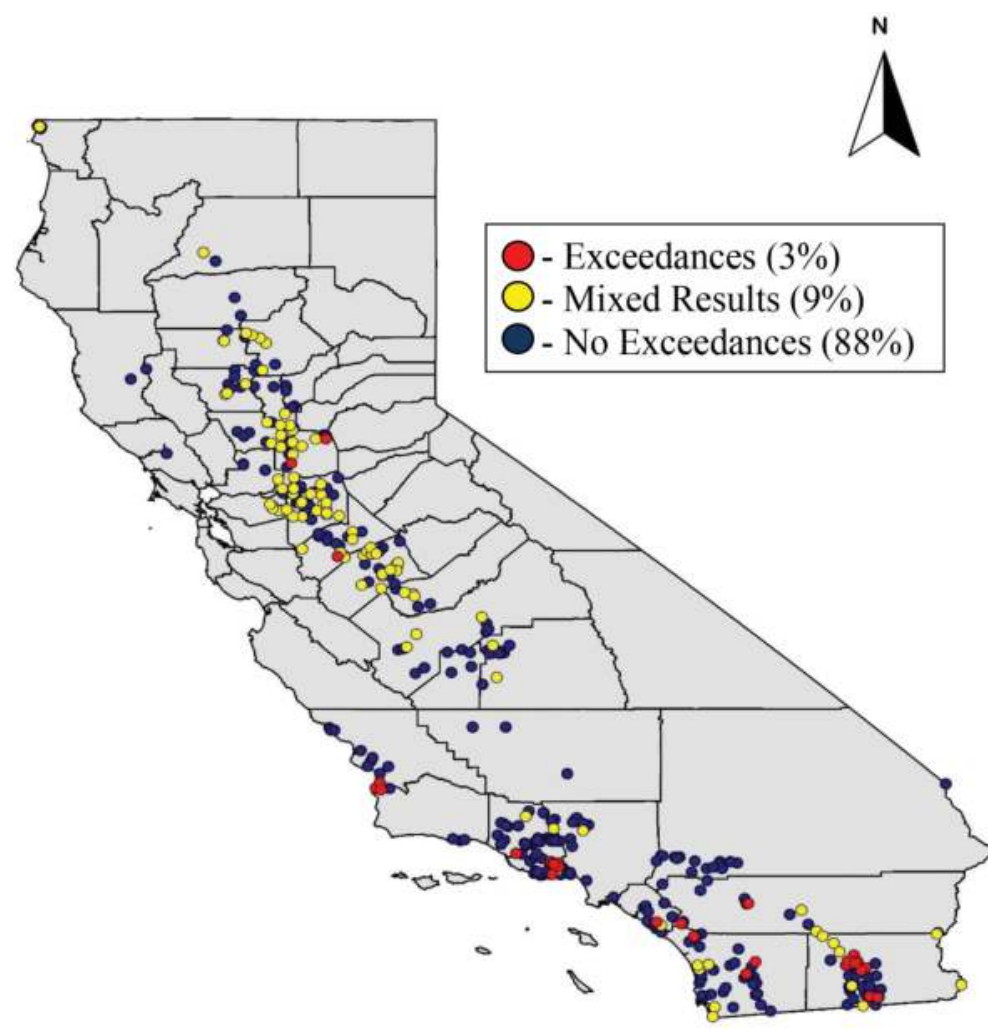

$0 \quad 200$ Kilometers

Figure 12. California bifenthrin water column monitoring sites from 2001 to 2017 that exceeded the $14.4 \mathrm{ng} / \mathrm{L}$ fifth centile based on an SSD using a log-normal distribution (red dots), did not exceed the fifth centile (blue dots) and mixed results of exceeding and not exceeding the fifth centile based on two or more measurements (yellow dots).

acute criterion and proposed chronic criterion of $0.01 \mathrm{ng} / \mathrm{L}$ do not provide any difference in the level of protection for aquatic life based on the current data set. Typically, the lower chronic criteria values offer a greater level of protection.

The use of the bifenthrin chronic value for predicting risk has uncertainty given the hydrophobic properties of bifenthrin which suggests that this pyrethroid would only remain in the water column for relatively short periods of time (corresponding with acute exposures) before partitioning to suspended and dissolved organic matter. However, due to the sorption/desorption properties of bifenthrin [34], chronic exposures to freely dissolved bifenthrin are certainly possible in the aquatic environment if benthic taxa remain in the depositional areas in streams for extended periods of time where these exposures may occur. 


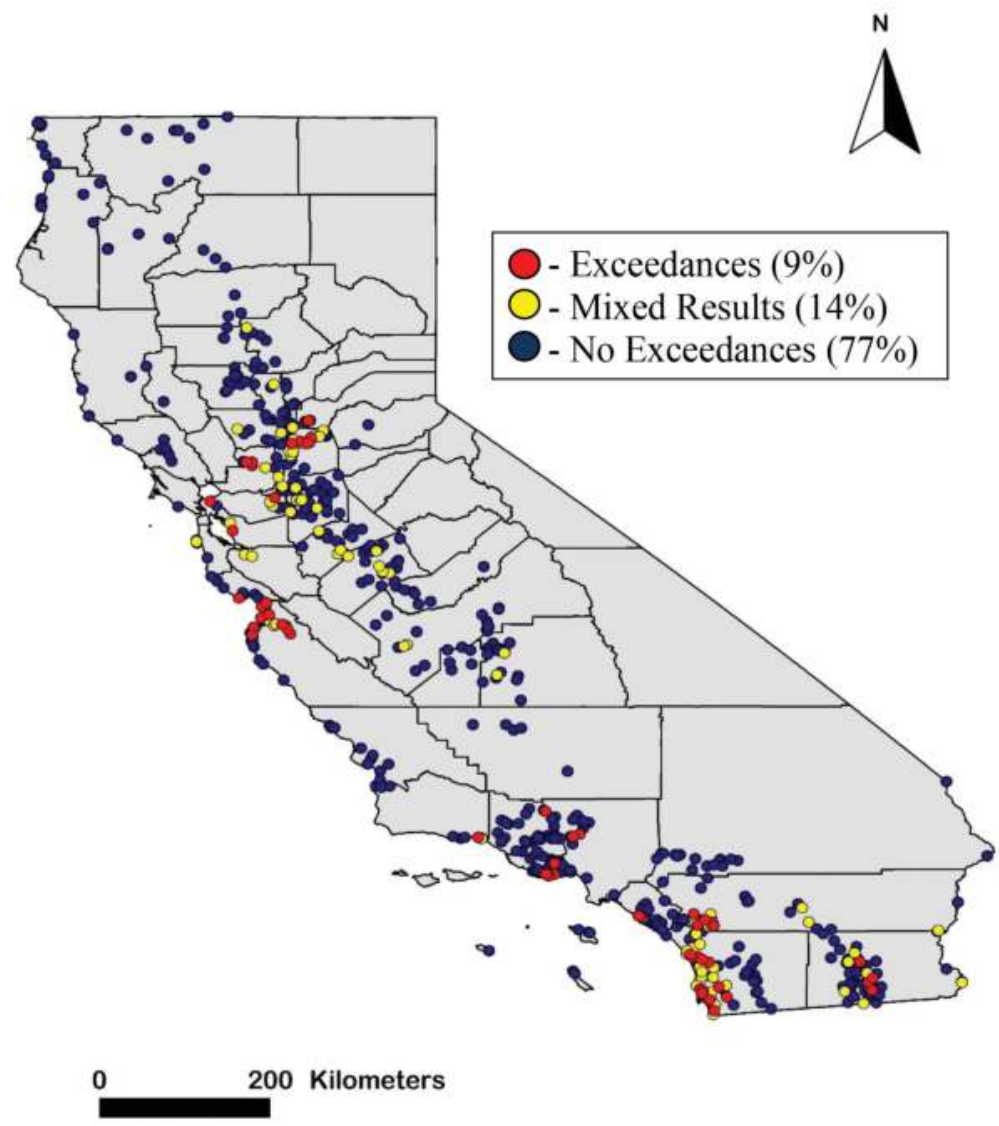

Figure 13. California bifenthrin water column monitoring sites from 2001 to 2017 that exceeded the $20150.06 \mathrm{ng} / \mathrm{L}$ regional board acute criterion (red dots), did not exceed the criterion (blue dots) and mixed results of exceeding and not exceeding the criterion based on two or more measurements (yellow dots).

A critical uncertainty issue with the comparison of whole water bifenthrin environmental concentrations and toxicity data derived from laboratory studies (primarily conducted with clean filtered water) is bioavailability. The bifenthrin measurements from natural whole water samples in the CEDEN monitoring data set can contain suspended and dissolved organic carbon matter which can bind bifenthrin and reduce or eliminate bioavailability to aquatic organisms [35]. Therefore, measurements of bifenthrin from whole water field samples overestimate the actual exposure concentration (bioavailable dissolved fraction) for resident taxa. Furthermore, a comparison of the environmental bifenthrin whole water measurements with toxicity data derived from laboratory filtered water is also an overestimation of ecological risk since only a small fraction (less than $10 \%$ - see [35]) of the environmental concentration is in the dissolved or bioavailable form. Additional research is recommended using a bioavailability 


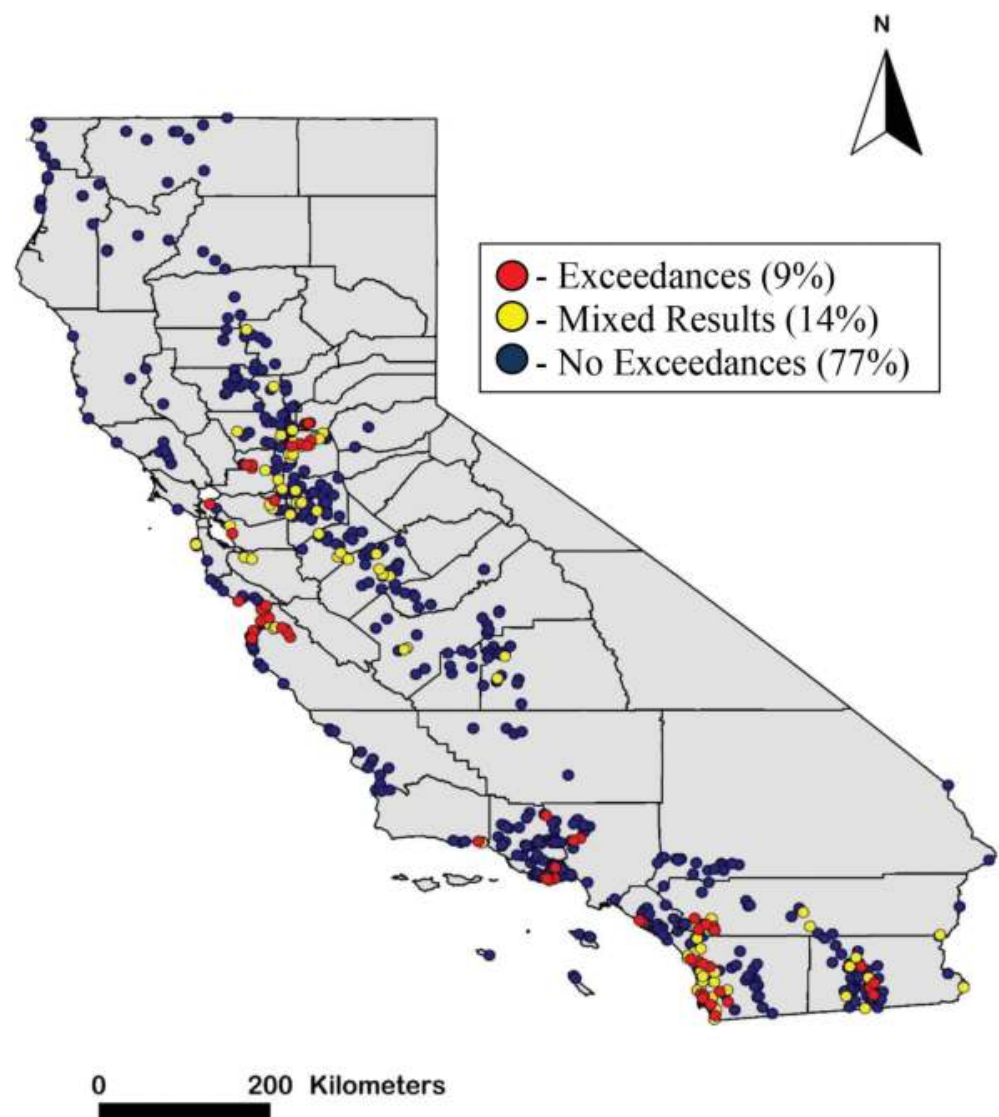

Figure 14. California bifenthrin water column monitoring sites from 2001 to 2017 that exceeded the $20150.01 \mathrm{ng} / \mathrm{L}$ regional board chronic criterion (red dots), did not exceed the chronic value (blue dots) and mixed results of exceeding and not exceeding the chronic value based on two or more measurements (yellow dots).

equation to convert whole water bifenthrin concentrations to the dissolved fraction so these dissolved values can be compared with regulatory thresholds.

\section{Conclusions}

The results from bifenthrin sediment mapping and toxicity evaluations conducted from 2001 to 2017 in California water bodies showed that bifenthrin measurements ranging from non-detected to $697.4 \mathrm{ng} / \mathrm{g} @ 1 \%$ TOC were available from depositional areas at 982 sites with concurrent TOC measurements. Thirty-six percent of these sites had measurements that were below the level of detection. Sediment toxicity data based on Hyalella azteca, Chironomus dilutus and Eohaustorius estuarius ambient toxicity tests were available for 499 
sites with concurrent bifenthrin measurements and $43 \%$ of these sites showed no significant toxicity. One percent of TOC normalized bifenthrin measurements reported from 982 sites showed no significant toxicity at $80 \%$ of the sites based on a Hyalella acute value of $6.1 \mathrm{ng} / \mathrm{g}$ while $99.5 \%$ of the sites showed no significant toxicity based on a Chironomus acute toxicity value of $177.5 \mathrm{ng} / \mathrm{g}$. The test species toxicity data (i.e., Hyalella or Chironomus) used to predict bifenthrin sediment toxicity in the field are critical as the use of Hyalella toxicity data (a highly sensitive species to bifenthrin) may be overprotective and this species may be less representative of most California water bodies when compared with Chironomids. Thirty-six percent of the 244 California sites with nondetected bifenthrin concentrations had some concurrent significant sediment toxicity thus suggesting that toxicity at these sites is due to factors other than bifenthrin.

All sediment measurements used in the current bifenthrin analysis were from depositional areas where bifenthrin is most likely to be measured if sources exist. However, available sediment mapping data from California streams suggest that depositional areas are not the dominant type wetted stream bed sediment in these water bodies, but rather these aquatic systems are dominated by nondepositional areas where bifenthrin is not likely to be found. Therefore, based on this information, ecological risk from bifenthrin sediment exposure to resident aquatic life in California water bodies is judged to be low statewide.

The results from bifenthrin mapping of water column and toxicity data conducted from 2001 to 2017 from California water bodies showed bifenthrin water column measurements were available from 716 sites and values from $77 \%$ of these sites were below the level of detection. Water column ambient toxicity data based on six different ambient test species were available for 467 sites with concurrent bifenthrin measurements, and 65\% of these sites showed no significant toxicity. Thirty-one percent of the 429 sites with nondetected bifenthrin concentrations showed some significant toxicity which suggests that toxicity at these sites is due to factors other than bifenthrin. A comparison of bifenthrin water column concentrations from 716 sites with a fifth centile $(14.4 \mathrm{ng} / \mathrm{L})$ from an SSD with 17 species showed no exceedances of this fifth centile at $88 \%$ of the sites. A comparison of bifenthrin water column concentrations from 716 sites using an acute provisional criterion of $0.06 \mathrm{ng} / \mathrm{L}$ or a proposed provisional chronic criterion of $0.01 \mathrm{ng} / \mathrm{L}$ showed no exceedances at $77 \%$ of the sites.

The ecological risk from water column exposures of bifenthrin to aquatic life in California water bodies is generally judged to be low statewide based on the following: (1) relatively few detected bifenthrin concentrations over a 17-year period (only $16 \%$ of the samples); (2) $77 \%$ of the samples did not exceed proposed acute or chronic bifenthrin criterion; (3) the hydrophobic properties of bifenthrin (binding to organic matter) eliminate or greatly reduce bioavailability from water exposures to aquatic organism; and (4) comparison of environmental whole water concentrations of bifenthrin with toxicity values used in the proposed UC Davis criteria based on filtered (bioavailable) concentrations is an overestimation of ecological risk. Future research is needed to convert total water bifenthrin measurements to the dissolved phase in order to accurately compare these values with regulatory thresholds. 


\section{Acknowledgements}

We acknowledge FMC Agricultural Products for sponsoring this study.

\section{Conflict of interest}

The authors declare they have no conflict of interest.

\section{Author details}

Lenwood W. Hall Jr* and Ronald D. Anderson

*Address all correspondence to: 1whall@umd.edu

University of Maryland, Wye Research and Education Center, Maryland, USA

\section{References}

[1] Spurlock F, Lee M. Synthetic pyrethroid use patterns, properties, and environmental effects. In: Gan J, Spurlock F, Hendley P, Weston D, editors. Synthetic Pyrethroids: Occurrence and Behavior in Aquatic Environments. Vol. 991. Washington, DC: American Chemical Society Symposium Series; 2008. pp. 3-25

[2] Aquatic Science Center. The Pulse of the Delta: Monitoring and Managing Water Quality in the Sacramento-San Joaquin Delta. Rethinking Water Quality Monitoring. Contribution 630. Oakland, CA: Aquatic Science Center; 2012

[3] Ng CM, Weston DP, You J, Lydy MJ. Patterns of pyrethroid contamination and toxicity in agricultural and urban stream segments. In: Gan J, Spurlock F, Hendley P, Weston D, editors. Synthetic Pyrethroids: Occurrence and Behavior in Aquatic Environments. Vol. 991. Washington, DC: American Chemical Society Symposium Series; 2008. pp. 355-369

[4] Hunt J, Markiowicz B, Pranger M. Summary of Toxicity in California Waters: 2001-2009. Sacramento, CA: State of California Surface Water Ambient Monitoring Program; 2010

[5] Hall LW, Anderson RD. Spatial analysis of bifenthrin sediment concentrations in California waterbodies from 2001 to 2010: Identification of toxic and non-toxic areas. Human and Ecological Risk Assessment. 2012;20:497-509

[6] Fojut TL. Water quality criteria report for bifenthrin. Updated report. May 2015. Central Valley Regional Water Quality Control Board. Available from: http://www.swrcb.ca.gov/ rwqcb5/water_issues/tmdl/central_valley_projects/central_valley_pesticides/criteria_ method/index.shtml. [Accessed: Oct 4, 2017] 
[7] Hall LW, Anderson RD. Mapping Sites in California Waterbodies where Bifenthrin Sediment Concentrations have been Measured from 2001 to 2017: Identification of Toxic and Non-Toxic Areas. Queenstown, MD: Report prepared by the University of Maryland Wye Research and Education Center; 2018

[8] Hall LW, Anderson RD. Mapping Sites in California Waterbodies where Bifenthrin Water Column Concentrations have been Measured from 2001 to 2017: Identification of Toxic and Non-Toxic Areas. Queenstown, MD: Report prepared by the University of Maryland Wye Research and Education Center; 2018

[9] Amweg EL, Weston DP, Ureda NM. Use and toxicity of pyrethroid pesticides in Central Valley, California USA. Environmental Toxicology and Chemistry. 2005;24:966-972

[10] Maul JD, Trimble AJ, Lydy MJ. Partitioning and matrix specific toxicity of bifenthrin among sediments and leaf sourced organic matter. Environmental Toxicology and Chemistry. 2008;27:945-952

[11] Weston DP, Jackson CJ. Use of engineered enzymes to identify organophosphate and pyrethroid related toxicity in toxicity identification evaluations. Environmental Science and Technology. 2009;43:5514-5520

[12] Weston DP, You J, Hawood AD, Lydy MJ. Use of whole sediment toxicity identification evaluation tools for pyrethroid insecticides. III. Temperature manipulation. Environmental Toxicology and Chemistry. 2009;28:173-180

[13] Trimble AJ, Belden JB, Mueting SA, Lydy MJ. Determining modifications of bifenthrin toxicity and sediment binding affinity from various potassium chloride concentrations in overlying water. Chemosphere. 2010;80:53-59

[14] Putt AE. Bifenthrin Toxicity to Midge (Chironomus tentans) During a 10-d Exposure. Report, Springborn Smithers Laboratory Study No. 13656.6106. Wareham, MA; 2005

[15] Picard CR. 10-d Toxicity Test Exposing Midges (Chironomus dilutus) to Bifenthrin Applied to Formulated Sediment under Static Renewal Conditions following OPPTS Draft Guidelines. 850-1735. Springborn Smithers Laboratory Study No. 13656.6143. Wareham, MA; 2010

[16] Anderson BS, Phillips BM, Hunt JW, Worcester K, Richard N, Tjeerdema RS. Identifying primary stressors impacting macroinvertebrates in the Salinas River (CA, USA): Relative effects of pesticide and suspended particles. Environmental Pollution. 2006;141:402-408

[17] Guy D. Bifenthrin with Cladocerans Ceriodaphnia dubia in an Acute Definitive Test. Aquatic Toxicology Laboratory Report P-2161-2. California Department of Fish and Game, Aquatic Toxicology Lab, Elk Grove, CA; 2002

[18] Wheelock CE, Miller JL, Gee SJ, Shan G, Hammock BD. Development of toxicity identification evaluation procedures for pyrethroid detection using esterase activity. Environmental Toxicology and Chemistry. 2004;23:2699-2708 
[19] Hooftman RN, Rooseboom-Reimers A, Verhoff LRCW. Static Acute Toxicity Tests with the Insecticide Bifenthrin Technical and Six Arthropod Species. Study No. 01-2424/01. Delft, The Netherlands: TNO Chemistry. FMC Study No. A2003-5703; 2002

[20] Hoberg JR. Acute Toxicity of FMC 54800 Technical to Rainbow Trout (Salmo gairdneri). EG\&G Bionomics Report BW-83-8-1446. Wareham, MA: EG\&G Bionomics. FMC Study No. A1983-096; 1983

[21] Surprenant DC. Acute Toxicity of 14C-FMC-54800 to Rainbow Trout (Salmo gairdneri) under Flow through Conditions. Springborn Bionomics Report BW-85-2-1732. Wareham, MA: Springborn Bionomics. FMC Study No. A1984-140; 1985

[22] Hoberg JR. Acute Toxicity of FMC 54800 Technical to Bluegill (Lepomis macrochirus). EG\& G Bionomics Report BW-83-8-1445. Wareham, MA: EG\&G Bionomics. FMC Study No. A1983-0987; 1983

[23] Surprenant DC. Acute Toxicity of 14C-FMC-54800 to Bluegill (Lepomis macrochirus) under flow through Conditions. Springborn Bionomics Report BW-85-2-1730. Wareham, MA: Springborn Bionomics. FMC Study No. A1984-140; 1985

[24] McAllister WA. Full Life Cycle Toxicity of 14C-FMC 54800 to Fathead Minnow (Pimephales promelas) in a Flow Through System. FMC Study No. A1986-2100; 1988

[25] Guy D. Bifenthrin with Pimephales promelas in an acute definitive test. Aquatic Toxicology Laboratory Report P-2161-1. Elk Grove, CA: California Department of Fish and Game, Aquatic Toxicology Laboratory Lab; 2000

[26] Surprenant DC. Acute Toxicity of FMC 54800 Technical to Daphnia Magna. EG\&G Bionomics Report BW-83-8-1444. Wareham, MA: EG\&G Bionomics. FMC Study No. A1983098, 1983

[27] Surprenant DC. Acute Toxicity of 14C-FMC 54800 to Daphnia Magna under Flow-Through Conditions. Springborn Bionomics Report BW-85-2-1731. Wareham, MA: Springborn Bionomics. FMC Study No. A1984-140; 1985

[28] Siegfried BD. Comparative toxicity of pyrethroid insecticides to terrestrial and aquatic insects. Environmental Toxicology and Chemistry. 1993;12:1683-1689

[29] Puckett M. Quality Assurance Management Plan for the State of California's Surface Water Ambient Monitoring Program. Report Prepared for California's State Water Resources Control Board, Division of Water Quality. Sacramento, CA; 2002

[30] Hall LW, Anderson RD, Killen WD. Mapping the spatial extent of depositional areas in agricultural, urban and residential California streams: Implications for pyrethroid toxicity. Human and Ecological Risk Assessment. 2012;18:368-392

[31] Giddings JM, Wirtz JR. Compilation and Evaluation of Aquatic Toxicity Data for Synthetic Pyrethroids. Report \#07626. Lakewood, WA: Compliance Services International; 2012 
[32] Hall LW, Killen WD, Anderson RD, Alden RW III. A three year assessment of the influence of physical habitat, pyrethroids and metals on benthic communities in two urban California streams. Journal of Ecosystem and Ecography. 2013, 2013;3:133. DOI: 10.4172/ 2157-7625.1000133

[33] Hall LW, Anderson RD, Alden RW III. A ten-year summary of concurrent ambient water column and sediment toxicity tests in the Chesapeake Bay watershed: 1990-1999. Environmental Monitoring and Assessment. 2002;76:311-352

[34] Hendley P. Conceptual Models of Synthetic Pyrethroid Behavior in Aquatic Systems and Their Implications. Pyrethroid Working Group Ecological Risk Assessment Report Number PWG-ERA-03a. Valdosta, GA; 2014

[35] Hlidak ML, Kuivila KM. Assessing the occurrence and distribution of pyrethroids in water and suspended sediment. Journal of Agricultural and Food Chemistry. 2009;57:9079-9085 
